\title{
Establishment and Applied Research on a Wetland Ecosystem Evaluation Model in Taiwan
}

\author{
Han-Shen Chen ${ }^{1,2}$ \\ Received: 31 July 2015; Accepted: 12 November 2015; Published: 26 November 2015 \\ Academic Editor: Vincenzo Torretta \\ 1 School of Health Diet and Industry Management, Chung Shan Medical University, No. 110, Sec. 1, \\ Jianguo N. Rd., Taichung 40201, Taiwan; allen975@csmu.edu.tw; Tel.: +886-4-2473-0022 (ext. 12225); \\ Fax: +886-4-2324-8188 \\ 2 Department of Medical Management, Chung Shan Medical University Hospital, No. 110, Sec. 1, \\ Jianguo N. Rd., Taichung 40201, Taiwan
}

\begin{abstract}
There is rich biodiversity and biomass in wetlands and these areas are important in ecosystems. Assessment of the environment of wetlands is critical in the management of pivotal ecosystems. The energy ecological footprint (EEF) is an improved form of the ecological footprint method based on the theory of energy value. EEF can be a useful tool for comparing and monitoring environmental impacts. EEF was used to investigate a national coastal wetland in Taiwan; i.e., Gaomei Wetlands. We created a wetland ecosystem evaluation model to quantify the EEF, ecological safety of the Gaomei Wetlands, and energy ecological carrying capacity to assess the current environmental situation of the area between 2007 and 2013. The research results provide a reference for environmental policy execution, strategy, and planning and suggestions for sustainable development of the Gaomei Wetlands. Our study showed that the per capita ecological carrying capacity of the Gaomei Wetlands experienced fluctuations during the time of the study. However, the per capita EF had substantial growth. The per capita ecological carrying capacity of the Gaomei Wetlands was influenced by the EFs of the fossil energy land, meadows, and croplands.
\end{abstract}

Keywords: wetlands; ecosystem; energy ecological footprint; ecological security

\section{Introduction}

From the Millennium Ecosystem Assessment (MEA) of the UN of global ecosystems, wetlands are found to be the most adversely damaged ecosystem, and their biodiversity is severely threatened. The continuous loss and degradation of wetlands will gradually weaken the service function of ecosystems (such as food and timber ecosystems and cause decline in most other services such as flood control, genetic resources, or pollination) thereby diminishing the well-being of people [1]. Because wetlands were previously inexpensive and were considered useless, many countries changed these areas into urban land or used them for agricultural and industrial purposes without a framework of established laws and policy protection systems [2]. The past decade has seen the loss of approximately $30 \%$ to $50 \%$ of wetlands worldwide incurred by climate change and human damage $[3,4]$. In fact, wetlands are extremely important natural resources that provide seashore protection, flood regulation, underground water replenishment, fish and shellfish propagation, water purification, climate adjustment, and ecotourism destination development [5-9]. Kathiresan and Rajendran [10] noted that wetland flora, such as mangroves, can ease the impact of storm surges and tsunamis, minimizing the casualties and property damage that occur during these natural disasters. Wetland functions have garnered the attention of developed countries such as the UK, where legislation prohibits land reclamation and bans the use of industrial or agricultural districts 
converted from wetlands. The aim of such legislation in the UK is to recover original wetland landscapes and functions [2,11].

Since the 1960s, environmental planners have discussed the level of population growth and urban development that a city or a region could accommodate without endangering the environmental system from the perspective of environmental assimilative capacity or carrying capacity [12]. Barbier, Burgess, and Folke [13] thought that biocapacity is the maximum pressure that an ecosystem can bear. The pressure comes from social, economic, and cultural activities and is exerted directly or indirectly on the ecosystem leading to phenomena such as degradation of the environment and loss of species diversity. At present, research on ecological carrying capacity (ECC) focuses on evaluation methods and ECC application, particularly the use of quantitative analysis methods for direct or indirect evaluation of the ECC [14-16]. A study by Zhang, Yang, and $\mathrm{Yu}$ [17] suggested that, although the existing sustainability evaluation methods can be employed to determine the effects of human activities on various functions in the ecosystem, evaluation with these methods for assessment of the social economy is limited. Also, most studies have not discussed the trend of dynamic development. Improvement is needed in the assessment of ecosystem methods.

Intensive progress has been made in the last two decades in the use of two appraisal tools; i.e., ecological footprint (EF) and energy analysis (EA). EF is the index established for sustainability issues considering the notion that human consumption is dependent on the natural environment. EA involves quantitative analysis techniques that can be used to determine the value of services, resources, and commodities [18]. The two methods are performed with different approaches; however, both are intended to solve the same problem. Both methods account for resources and throughput and they estimate the gap between human demand and natural services. They also are used to evaluate resource utilization by humans.

The idea of energy synthesis to modify the basis of EF calculations has been introduced in recent years. Zhao, Li, and Li [19] proposed a new approach based on EF and EA. In this new approach, human consumption, based on six types of bioproductive areas, was translated into a common energy unit. The carrying capacity and energy-based EF were calculated for the year 2000 and defined based on a case study in Gansu Province, China. Because the energy ecological footprint (EEF) model is a static assessment in which a time variable is not included, most international empirical studies have adopted years as the unit for calculating the EEFs of countries or regions [20-22].

Chen, Chen, and Hsieh [23] used material flow, the EF method, and relevant indexes to estimate indicators of environmentally sustainable development for Taiwan during the period 1998 to 2005. The results showed that the per capita EF of Taiwan in 2005 was $6.5392 \mathrm{hm}^{2}$ and the per-capita ecological overshoot was $4.8569 \mathrm{hm}^{2}$, indicating that the production and living intensity of the population of Taiwan have outstripped the carrying capacity of the eco-economic system. Chen, Chen, and Hsieh [24] adopted EF and EA, established the Taiwan green economy index system, and compared the results with those of other countries. Their study showed that the per capita energy consumption and energy use intensity of Taiwan are low, and the environmental carrying capacity ratio is markedly high.

An increasing number of calculations have been derived from the EF idea in recent years. Various analytical concepts were used in these calculations. Most concepts, however, involved measuring the sustainable development of considering the area of biologically productive land that was necessary to facilitate human consumption and waste production. Particularly, the concept of energy conversion is the primary method for investigating EFs. An improved method for calculating EFs has been proposed based on the EA theory: the EEF $[25,26]$. The EEF is an improved model in which the EA is integrated with an EF framework, thereby using the EA theory to calculate EFs and ECCs. In this model, natural resources, various types of human consumption, and levels of energy flow are converted into a solar energy value based on energy transformity. The concept of energy density was subsequently introduced to convert the solar energy of each consumed item to a corresponding biologically productive area. This was then used to calculate the EF and EDD of the research site. 
The results were used to identify sustainable development conditions. Haberl, Erb, and Krausmann [27] observed that the success of EEF hinges on the use of simple quantitative indices to represent EFs and ECC for measuring and determining sustainability. Nguyen and Yamamoto [28] applied the EEF to calculate the EFs of biological and nonbiological components of nonrenewable resources consumed in Australia, Belgium, Brazil, Canada, Japan, the US, and Vietnam. Chen and Chen [29] applied EF and the EA theory to calculate the EFs for the years 1981 and 2001 and the ecological carrying capacities of China. The authors reported that both methods can be effectively used to assess resources, environments, human activities, and ecological overshoot. The carrying capacity and EF of cropland in Jiangsu Province, China, was also calculated based on EA by Liu, Lin, Feng, and Liu [30]. They used a time series case study and compared the results with results from a conventional EF study. An improved sustainability index in energy units was thought to result from a combination of EF and EA, according to Siche and colleagues [31,32], which was used as the basis for calculating EF equivalent factors. These factors were then evaluated for Peru and Brazil.

In summary, this study applied EEF to construct an evaluation model that is applicable to the assessment of wetland ECC and to quantify the EEFs and energy ecological carrying capacities (EECCs) of the Gaomei Wetland for the period 2007 to 2013. This evaluation model can be a systematic measurement tool used for promoting sustainable development and monitoring the progression and trends of sustainable development. The evaluation results can be used as a reference for planning and executing environmental policies. As a final outcome, suggestions and strategies are proposed, based on the study results, for sustainable development of the Gaomei Wetlands.

\section{Materials and Methods}

\subsection{Study Area}

The research site was Gaomei Wetlands $\left(24^{\circ} 18^{\prime} 35.07^{\prime \prime} \mathrm{N}, 120^{\circ} 33^{\prime} 08.21^{\prime \prime} \mathrm{E}\right)$, which is in Shimizu, Taichung, Taiwan. This town is comprised of more than 300 hectares in central Taiwan. In 2007, the Gaomei Wetlands were designated national wetlands. In recent years, the wetlands have become a crucial water bird habitat and a prominent bird-watching spot; however, human-caused disturbances, such as the construction of Provincial Highway 61 and wetland park development, have caused rapid losses of sand bars and mangroves and a decline in biodiversity. As a consequence, the ecological environment is considered to be endangered. The development of natural resources must typically consider the sustainable development of the economy, ecology, society, and mitigation of recreational impacts simultaneously. We therefore studied how the development and sustainable management of wetlands can help to protect the environmental ecosystem. Also, these efforts can bring into view critical environmental protection factors such as climate change and biodiversity.

\subsection{Method}

\subsubsection{Energy Ecological Footprint}

Zhao et al. [19] proposed this new approach based on EF and EA. In this new approach, human consumption was said to correspond to six types of basic bioproductive areas; e.g., croplands, fossil energy lands, forest lands, meadows, water, and building lands. These six areas were then translated into a common energy unit. Moreover, by introducing the concept of energy density (the amount of energy based on the unit area of all renewable resources), energy is converted to a more comprehensible area concept.

The energy conversion rate (transformity), which is commonly used in EA, is the energy value of the unit energy $(\mathrm{J})$ or material $(\mathrm{g})$, but the conversion rate of solar energy is used in the actual application; that is, the equivalent amount of joules of the solar energy conversion for a unit of energy or material. Using the energy conversion rate, various forms of energy in the ecosystem and/or the ecological economic system can be converted into the energy of the same standard for quantification 
and analysis. At the same time, the energy conversion rate is a measurement of the energy value (energy quality).

Once the Gaomei Wetlands system was defined and mapped, and the flows were quantified, the conversion of energy and/or mas to energy was compiled. To do this, the quantified flows of the wetlands in units of mass and energy were multiplied by the corresponding transformity values of the flows using Equation (1):

$$
\operatorname{energy}(\text { sej) }=\text { energy or mass }(\text { jor g) } \times \text { transformity }(U E V s)(\text { sej/J, g) }
$$

The resources and consumption data in terms of energy and/or mass flows and converts the data to solar emjoules (sej) in the EEF calculation, using the respective unit energy values (UEVs). Next, the EEF and ECC are estimated using the empower density (sej/ha; global empower density in the carrying capacity calculation and also the footprint calculation). Subsequently, calculating the sum of the amount of energy that corresponds to the actual consumption amount in bioproductive areas yields the amount of energy consumed per capita $\left(c_{i}\right)$, which is then divided by the regional energy density $\left(P_{1}\right)$ to obtain the per capita EEF (ef). Equation (2) is expressed as follows:

$$
\text { ef }=\sum_{i=1}^{n} a_{i}=\sum_{i=1}^{n} c_{i} / P_{1}
$$

where $i$ represents the type of consumed resource; ef represents the per capita EEF; $a_{i}$, the area corresponding to the amount of the $i$ th resource consumed per capita; $c_{i}$, the amount of per capita energy consumed from the $i$ th resource (unit is sej); and $P_{1}$, the total acquired regional energy per regional area (unit sej $/ \mathrm{m}^{2}$ ).

EECC is the ratio of the energy of all renewable resources in the research site to the mean global energy density. When calculating the regional EECC, the energy amount of renewable resources that can be obtained by the regional population should be calculated first. Solar radiation energy, rain chemical energy, wind energy, rotational energy of the earth, and rain geopotential are all considered as renewable resources. Additionally, to prevent repeated calculation, the maximum value is used as the total energy acquired in a region to obtain the amount of energy per capita of resource supply $(e)$,

$$
e c=e / P_{2}
$$

where $e c$ represents the per capita EECC, $e$ represents the energy per capita of resource supply, and $P_{2}$ represents the global energy density.

The work of Odum (published in Energy Folio) was used to determine global energy or baseline. This publication suggested a new baseline of $1.583 \times 10^{25}$ sej. The total surface area of the earth has been calculated to be $5.1 \times 10^{14} \mathrm{~m}^{2}$. Therefore, the energy density $\left(P_{2}\right)$ is calculated by the following equation (Equation (4)):

$$
P_{2}=\text { total energy of the earth } / \text { the area of the earth }=\frac{1.583 \times 10^{25}{ }_{s e j}}{5.1 \times 10^{14}{ }_{m^{2}}}=3.1 \times 10^{10} \mathrm{sej} / \mathrm{m}^{2} a
$$

The global empower density was used in this paper as the conversion factor from energy flows for biocapacity and footprint to areal units, which facilitated a comparison of the measurements.

\subsubsection{Dynamic Analysis and Evaluation of Ecological Security}

In this study, because the EF per unit area can objectively reflect the pressure acting on an ecological environment, we adopt the ecological footprint pressure index (EFI) to measure regional ecological security. Theoretically, an intense ecological pressure signifies a low level of ecological security (ES). 
The ratio of the per capita EEF (ef) to the per capita EECC (ec) of renewable resources is the definition of EFI. EFI levels are shown in Table 1. The computational formula is given in Equation (5):

$$
E F I=e f / e c
$$

where EFI represents the EF pressure index, ef denotes the per capita EEF of renewable resources, and $e c$ represents the per capita EECC.

Because $e f>0$ and $e c>0$, when $0<\mathrm{EFI}<1, e f<e c$, the ecological resource supply is greater than demand, and the region is in an ES state; when EFI $=1$, ef $=e c$, ecological resource supply and demand reach a balance, and the region is in an ES critical state; when EFI $>1, e f>e c$, and the pressure on the per unit biocapacity area is greater than the supporting capacity can provide. Therefore, supply and demand are inequivalent, and ES is threatened; the greater the EFI deviates from 1, the greater the degree of ecological insecurity.

Table 1. The classification of ecological security.

\begin{tabular}{cccccc}
\hline Degree & State & Index Range & Degree & State & Index Range \\
\hline 1 & Good & EFI $<0.5$ & 3 & Poor & EFI $=0.8-1.0$ \\
2 & Fair & EFI $=0.5-0.8$ & 4 & Bad & EFI $>1.0$ \\
\hline
\end{tabular}

\section{Results and Discussion}

\section{Calculation and Analysis of EEF and EECC}

Five renewable resources; i.e., wind energy, solar radiation energy, rain geopotential, rain chemical energy, and the rotational energy of the earth were included in the model. The renewable resources were multiplied by their corresponding solar energy conversion ratio to obtain the corresponding amount of solar energy. This study applied this equation to calculate the 2007 to 2013 solar energy of the renewable resources in Gaomei Wetlands (Table 2), of which rain geopotential had the greatest solar energy. Additionally, the solar energy of rain geopotential and rain chemical energy differed significantly during the study period. One reason could be the large variations in the amount of precipitation per year. In addition, the solar energy of the wind energy, solar radiation energy, and the rotational energy of the earth was unchanged.

Table 2. Solar energy of the renewable resources in Gaomei Wetlands, 2007-2013.

\begin{tabular}{cccccc}
\hline Year & $\begin{array}{c}\text { Solar Radiation } \\
\text { Energy (sej) }\end{array}$ & $\begin{array}{c}\text { Wind Energy } \\
\text { (sej) }\end{array}$ & $\begin{array}{c}\text { Rain } \\
\text { Geopotential } \\
\text { (sej) }\end{array}$ & $\begin{array}{c}\text { Rain Chemical } \\
\text { Energy (sej) }\end{array}$ & $\begin{array}{c}\text { Rotational } \\
\text { Energy of the } \\
\text { Earth (sej) }\end{array}$ \\
\hline 2007 & $5.98 \times 10^{21}$ & $1.82 \times 10^{20}$ & $3.96 \times 10^{22}$ & $3.48 \times 10^{23}$ & $3.23 \times 10^{22}$ \\
2008 & $5.01 \times 10^{21}$ & $1.83 \times 10^{20}$ & $3.75 \times 10^{22}$ & $3.56 \times 10^{23}$ & $3.26 \times 10^{22}$ \\
2009 & $6.02 \times 10^{21}$ & $1.85 \times 10^{20}$ & $3.62 \times 10^{22}$ & $3.61 \times 10^{23}$ & $3.25 \times 10^{22}$ \\
2010 & $6.05 \times 10^{21}$ & $1.86 \times 10^{20}$ & $3.22 \times 10^{22}$ & $3.72 \times 10^{23}$ & $3.27 \times 10^{22}$ \\
2011 & $6.10 \times 10^{21}$ & $1.88 \times 10^{20}$ & $3.96 \times 10^{22}$ & $3.82 \times 10^{23}$ & $3.30 \times 10^{22}$ \\
2012 & $6.12 \times 10^{21}$ & $1.91 \times 10^{20}$ & $4.25 \times 10^{22}$ & $3.91 \times 10^{23}$ & $3.35 \times 10^{22}$ \\
2013 & $6.16 \times 10^{21}$ & $1.92 \times 10^{20}$ & $4.57 \times 10^{22}$ & $4.32 \times 10^{23}$ & $3.41 \times 10^{22}$ \\
\hline
\end{tabular}

In this report we present a calculation of the footprint based on EEF for the Gaomei Wetlands in Taiwan. The consumption and production of the various resources are translated into a common unit area that can provide a true measure of the carrying capacity of the EF.

All footprint components were calculated and summed to obtain the total EEF using Equation (2). Table 3 shows the results of the EEF accounting. The per capita EEF (ef) in the year 2013 was $8.67\left(\mathrm{~m}^{2} / \mathrm{cap}\right)$. The category with the greatest amount of EEF is forest land $\left(8.92 \times 10^{-2} \mathrm{~m}^{2}\right)$, which 
corresponds to $47.47 \%$ of total EEF; the second category is fossil energy land $\left(4.64 \mathrm{~m}^{2}\right)$, which corresponds to $21.87 \%$ of total EEF.

Table 3. EEFs for the Gaomei Wetlands, 2007-2013.

\begin{tabular}{|c|c|c|c|c|c|c|c|}
\hline Year & $\begin{array}{l}\text { Cropland } \\
\left(\mathrm{m}^{2}\right)\end{array}$ & $\begin{array}{l}\text { Forest Land } \\
\qquad\left(\mathrm{m}^{2}\right)\end{array}$ & $\begin{array}{c}\text { Meadow } \\
\left(\mathrm{m}^{2}\right)\end{array}$ & $\begin{array}{l}\text { Fossil Energy } \\
\text { Land }\left(\mathrm{m}^{2}\right)\end{array}$ & Water $\left(\mathrm{m}^{2}\right)$ & $\begin{array}{l}\text { Building } \\
\text { Land }\left(\mathrm{m}^{2}\right)\end{array}$ & $\begin{array}{c}\text { Per Capita EEF } \\
\left(\mathrm{m}^{2} / \text { cap }\right)\end{array}$ \\
\hline 2007 & $6.71 \times 10^{-1}$ & $2.13 \times 10^{-1}$ & $6.87 \times 10^{-1}$ & 1.59 & $7.41 \times 10^{-2}$ & $3.51 \times 10^{-1}$ & 3.54 \\
\hline 2008 & $7.37 \times 10^{-1}$ & $2.75 \times 10^{-1}$ & $8.01 \times 10^{-1}$ & 2.02 & $1.58 \times 10^{-2}$ & $3.78 \times 10^{-1}$ & 4.26 \\
\hline 2009 & 2.54 & $3.08 \times 10^{-2}$ & $8.93 \times 10^{-1}$ & 2.78 & $1.62 \times 10^{-2}$ & $5.45 \times 10^{-1}$ & 5.37 \\
\hline 2010 & 1.95 & $3.26 \times 10^{-2}$ & $9.48 \times 10^{-1}$ & 3.08 & $1.38 \times 10^{-2}$ & $6.02 \times 10^{-1}$ & 5.92 \\
\hline 2011 & $2.13 \times 10^{-1}$ & $4.28 \times 10^{-2}$ & 1.51 & 4.3 & $1.86 \times 10^{-2}$ & 1.36 & 7.28 \\
\hline 2012 & 2.65 & $3.96 \times 10^{-2}$ & 1.96 & 4.74 & $1.97 \times 10^{-2}$ & 1.62 & 7.61 \\
\hline 2013 & 1.93 & $8.92 \times 10^{-2}$ & 2.17 & 4.64 & $2.04 \times 10^{-2}$ & 1.57 & 8.67 \\
\hline
\end{tabular}

According to Equation (3), Table 4 shows the EECC. The per capita EECC (ec) for the year 2007 was $3.18\left(\mathrm{~m}^{2} /\right.$ cap). The per capita EECC (ec) for the year 2013 was $3.72\left(\mathrm{~m}^{2} / \mathrm{cap}\right)$. Although per capita EECC (ec) exhibited small-scale fluctuations, the overall value remained unchanged. The reason for this might be that although environmental pollution and ecological damage generated by human activities somewhat reduced the regional ECC, the self-adjusting ability of natural environments allowed recovery within a certain period. Therefore, the ECC increased gradually. Additionally, in recent years, the government has frequently promoted ecological construction activities in the Gaomei Wetland, which has prevented stability in ECC and improved the self-adjusting capabilities of the ecosystem.

Table 4. EECCs for the Gaomei Wetlands, 2007-2013.

\begin{tabular}{ccccc}
\hline Year & $\begin{array}{c}\text { Solar Energy } \\
(\mathbf{s e j})\end{array}$ & $\begin{array}{c}\text { Per Capita Energy } \\
\left(\mathbf{m}^{2} / \mathbf{c a p}\right)\end{array}$ & $\begin{array}{c}\text { Per Capita EECC } \\
\left(\mathbf{m}^{\mathbf{2}} / \mathbf{c a p}\right)\end{array}$ & $\begin{array}{c}\text { Regional EECC } \\
\left(\mathbf{m}^{\mathbf{2}} \mathbf{)}\right.\end{array}$ \\
\hline 2007 & $4.64 \times 10^{23}$ & $2.02 \times 10^{16}$ & 3.18 & $1.08 \times 10^{8}$ \\
2008 & $3.61 \times 10^{23}$ & $1.58 \times 10^{16}$ & 3.54 & $1.00 \times 10^{8}$ \\
2009 & $3.23 \times 10^{23}$ & $1.16 \times 10^{16}$ & 3.63 & $1.02 \times 10^{8}$ \\
2010 & $3.36 \times 10^{23}$ & $1.30 \times 10^{16}$ & 3.82 & $1.01 \times 10^{8}$ \\
2011 & $3.09 \times 10^{23}$ & $1.09 \times 10^{16}$ & 3.70 & $1.03 \times 10^{8}$ \\
2012 & $3.92 \times 10^{23}$ & $1.13 \times 10^{16}$ & 3.63 & $1.01 \times 10^{8}$ \\
2013 & $3.27 \times 10^{23}$ & $1.17 \times 10^{16}$ & 3.72 & $1.01 \times 10^{8}$ \\
\hline
\end{tabular}

The per capita EECC and per capita EEF were used to calculate the 2007 to 2013 EFIs of the Gaomei Wetlands (Table 5). The results show that the EFI of the Gaomei Wetlands increased from 1.01 in 2007 to 2.11 in 2013, indicating that the ecological environment is constantly subjected to stress to the point where ES is threatened. As ecological pressure is mitigated, the ecological environment becomes more secure. Conversely, as the ecological pressure increases, ES decreases. When the ecological pressure increases to a certain level, the ecological environment is unsafe. To simplify, a drastic increase in EFI to a steady increase reflects a transition from a safe state to an unsafe state in the ecological environment. Therefore, the slow changing threshold of EFI was applied to verify the level of ecological security.

Table 5. 2007-2013 EFIs of the Gaomei Wetlands.

\begin{tabular}{cccccccc}
\hline Year & $\mathbf{2 0 0 7}$ & $\mathbf{2 0 0 8}$ & $\mathbf{2 0 0 9}$ & $\mathbf{2 0 1 0}$ & $\mathbf{2 0 1 1}$ & $\mathbf{2 0 1 2}$ & $\mathbf{2 0 1 3}$ \\
\hline EFI & 1.01 & 1.05 & 1.34 & 1.41 & 1.78 & 1.94 & 2.11 \\
ES level & 4 & 4 & 4 & 4 & 4 & 4 & 4 \\
ES evaluation & $\mathrm{Bad}$ & $\mathrm{Bad}$ & $\mathrm{Bad}$ & $\mathrm{Bad}$ & $\mathrm{Bad}$ & $\mathrm{Bad}$ & $\mathrm{Bad}$ \\
\hline
\end{tabular}


Technological, social, environmental, and economic issues must be included in indicators or methodology for sustainability assessments with a systemic perspective. Documentation has been performed to show the advantages of multi-metric assessment systems. Multi-metric assessments, as compared to single metric indices, allow measurements that are relatively less sensitive to extreme values [31,33]. In summary, EA is a powerful tool that is scientifically based on theory. However, the communication methods for results should be improved for general understanding and acceptance. Also, EF is a pedagogic instrument that can show the human impact on Earth. The instrument has some shortcomings, however, such as arbitrary boundary systems that do not consider the quality of energy and do not account for water demand and soil loss. These shortcomings should be overcome to expect robust results. Finally, different types of wetlands may have different stressors and may vary in their susceptibility to stressors. EFI was useful for measuring regional ES in this study. In theory, intense ecological pressure indicates low levels of ecological security. Our study employed four levels $(1=$ good, 2 = fair, $3=$ poor, and $4=$ bad $)$ of ecological security, however, this method represents only some of the complexity of sustainability.

The conclusion of this study is that the EEF method is more reliable for demonstrating the goods or service load on the environment than the conventional EA or EF indicator.

\section{Conclusions}

We used the EEF method to calculate the carrying capacity and EF of the Gaomei Wetlands on the west coast of Taiwan. We also analyzed the various components of the EEF. A comprehensive evaluation method incorporating EFI and DS in addition to the EEF method was used to evaluate the ES of the Gaomei Wetlands. We came to the following conclusions:

(a) According to the EEF model used for calculating the 2007 to 2013 ECCs and EFs of the Gaomei Wetlands, the per capita ECCs of the Gaomei Wetlands exhibited fluctuations during this period, whereas the per capita EFs showed substantial growth. The EFs of fossil fuel lands, croplands, and meadows considerably influenced the per capita ECC of the Gaomei Wetlands.

(b) I employed the EEF model to calculate ecological deficits and surpluses. Additionally, EFIs were obtained for comprehensive analysis and evaluation of ecological security for the period 2007 to 2013. The results indicated that during the period 2007 to 2013, the ecological environment of the Gaomei Wetland was in a safe state; however, the related indices increased every year.

In this study, the topography and ecological environment of the Gaomei Wetlands were observed to be similar to those of other coastal wetlands in Taiwan. Therefore, the evaluation model established can be applied to assess similar wetland ecological systems.

The innovations and contributions of this study are as follows. (a) The EEF theory was applied using a quantitative analysis of a coastal wetland and was effective for ES evaluation. (b) A time-sequence analysis was employed to overcome the static defects of traditional EFs.

Acknowledgments: I am thankful to the Ministry of Science and Technology (Republic of China, Taiwan) for financially supporting this research project (grant number NSC 102-2410-H-040-010).

Conflicts of Interest: The author declares no conflict of interest.

\section{References}

1. Millennium Ecosystem Assessment (MEA). Ecosystems and Human Well-being: Wetlands and Water Synthesis; World Resources Institute: Washington, DC, USA, 2005.

2. Kim, S.G. The evolution of coastal wetland policy in developed countries and Korea. Ocean Coast. Manag. 2010, 53, 562-569. [CrossRef]

3. Valiela, I.; Fox, S.E. Managing coastal wetlands. Science 2008, 319, 321-323. [CrossRef] [PubMed]

4. Miththapala, S. Mangroves. Coastal Ecosystems Series Volume 2; Ecosystems and Livelihoods Group Asia, International Union for Conservation of Nature: Colombo, Sri Lanka, 2008. 
5. Zedler, J.B.; Kercher, S. Wetland resources: Status, trends, ecosystem services, and restorability. Ann. Rev. Environ. Resour. 2005, 30, 39-74. [CrossRef]

6. Yang, W.; Chang, J.; Xu, B.; Peng, C.; Ge, Y. Ecosystem service value assessment for constructed wetlands: A case study in Hangzhou, China. Ecol. Econ. 2008, 68, 116-125. [CrossRef]

7. Fletcher, S.; Kawabe, M.; Rewhorn, S. Wetland conservation and sustainable coastal governance in Japan and England. Mar. Pollut. Bull. 2011, 62, 956-962. [CrossRef] [PubMed]

8. Feng, M.; Liu, S.; Euliss, N.H., Jr.; Young, C.; Mushet, D.M. Prototyping an online wetland ecosystem services model using open model sharing standards. Environ. Model. Softw. 2011, 26, 458-468. [CrossRef]

9. Su, C.H.; Fu, B.J.; He, C.S.; Lu, Y.H. Variation of ecosystem services and human activities: A case study in the Yanhe Watershed of China. Acta Oecol. 2012, 44, 46-57. [CrossRef]

10. Kathiresan, K.; Rajendran, N. Coastal mangrove forests mitigated tsunami. Estuar. Coast Shelf Sci. 2005, 65, 601-606. [CrossRef]

11. Lydie, G.G. Perceptions and attitudes toward de-polderisation in Europe: A comparison of five opinion surveys in France and the UK. J. Coast. Res. 2007, 23, 1218-1230.

12. Yue, Q.; Hou, L.; Wang, T.; Wang, L.; Zhu, Y.; Wang, X.; Cheng, X. Optimization of industrial structure based on water environmental carrying capacity in Tieling City. Water Sci. Technol. 2015, 71, 1255-1262. [CrossRef] [PubMed]

13. Barbier, E.; Burgess, J.; Folke, C. Paradise Lost? The Ecological Economics of Biodiversity; Earthscan Publications Limited: London, UK, 1994.

14. Brown, M.T.; Ulgiati, S. Energy measures of carrying capacity to evaluate economic investments. Popul. Environ. 2001, 22, 471-472. [CrossRef]

15. Xu, L.; Kang, P.; Wei, J. Evaluation of urban ecological carrying capacity: A case study of Beijing, China. Energy Policy 2010, 2, 1873-1880. [CrossRef]

16. Zeng, C.; Liu, Y.; Liu, Y.; Hu, J.; Bai, X.; Yang, X. An integrated approach for assessing aquatic ecological carrying capacity: A case study of Wujin District in the Tai Lake Basin, China. Int. J. Environ. Res. Public Health 2011, 8, 264-280. [CrossRef] [PubMed]

17. Zhang, Y.; Yang, Z.; Yu, X. Measurement and evaluation of interactions in complex urban ecosystem. Ecol. Model. 2006, 96, 77-89. [CrossRef]

18. Brown, M.T.; Ulgiati, S. Understanding the global economic crisis: A biophysical perspective. Ecol. Model. 2011, 223, 4-13. [CrossRef]

19. Zhao, S.; Li, Z.Z.; Li, W.L. A modified method of ecological footprint calculation and its application. Ecol. Model. 2005, 185, 65-75. [CrossRef]

20. Gronlund, E.; Klang, A.; Falk, S.; Hanaeus, J. Sustainability of wastewater treatment with microalgae in cold climate evaluated with energy and socio-ecological principles. Ecol. Eng. 2004, 22, 155-174. [CrossRef]

21. Han, X.Z.; Zhang, Y.Y.; Li, Z.Z. A new approach to trend extrapolation of time series of ecological footprint and its application. Acta Prataculturae Sin. 2006, 15, 129-134.

22. Siracusa, G.; LaRosa, A.D. Design of a constructed wetland for wastewater treatment in a Sicilian town and environmental evaluation using the energy analysis. Ecol. Model. 2006, 197, 490-497. [CrossRef]

23. Chen, Y.; Chen, C.Y.; Hsieh, T. Establishment and applied research on environmental sustainability assessment indicators in Taiwan. Environ. Monit. Assess. 2009, 155, 407-417.

24. Chen, Y.; Chen, C.Y.; Hsieh, T. Exploration of sustainable development by applying green economy indicators. Environ. Monit. Assess. 2011, 182, 279-289. [CrossRef] [PubMed]

25. Brown, M.T.; Ulgiati, S. Emergy evaluations and environmental loading of electricity production systems. J. Clean. Prod. 2002, 10, 321-334. [CrossRef]

26. Zhao, Y.Z.X.; Zou, Y.; Cheng, H. Assessing the ecological security of the Tibetan plateau: Methodology and a case study for Lhaze County. J. Environ. Manag. 2006, 80, 120-131. [CrossRef] [PubMed]

27. Haberl, H.; Erb, K.H.; Krausmann, F. How to calculate and interpret ecological footprint for long periods of time: The case of Austria 1926 to 1995. Ecol. Econ. 2001, 38, 25-45. [CrossRef]

28. Nguyen, H.X.; Yamamoto, R. Modification of ecological footprint evaluation method to include non-renewable resource consumption using thermodynamic approach. Resour. Conserv. Recycl. 2007, 51, 870-884. [CrossRef]

29. Chen, B.; Chen, C.O. Modified ecological footprint accounting and analysis based on embodied energy-A case study of the Chinese society 1981-2001. Ecol. Econ. 2007, 61, 355-376. [CrossRef] 
30. Liu, Q.P.; Lin, Z.S.; Feng, N.H.; Liu, Y.M. A modified model of ecological footprint accounting and its application to cropland in Jiangsu, China. Pedosphere 2008, 18, 154-162. [CrossRef]

31. Siche, R.; Agostinho, F.; Ortega, E. Emergy net primary production (ENPP) as basis for calculation of ecological footprint. Ecol. Indic. 2010, 10, 475-483. [CrossRef]

32. Ortega, E.; Pereira, L. A modified footprint method: The case study of Brazil. Ecol. Indic. 2012, 16, $113-127$.

33. Galli, A.; Wiedmann, T.; Ercin, E.; Knoblauch, D.; Ewing, B.; Giljum, S. Integrating ecological, carbon and water footprint into a footprint family of indicators: Definition and role in tracking human pressure on the planet. Ecol. Indic. 2012, 16, 100-112. [CrossRef]

(C) 2015 by the author; licensee MDPI, Basel, Switzerland. This article is an open access article distributed under the terms and conditions of the Creative Commons by Attribution (CC-BY) license (http:/ / creativecommons.org/licenses/by/4.0/). 